\title{
EDUCAÇÃO EMPREENDEDORA NO ENSINO DE ADMINISTRAÇÃO: A SIMULAÇÃO REALÍSTICA COMO INSTRUMENTO DIDÁTICO
}

Cristiano Valério Ribeiro ${ }^{1}$ Alan Ferreira De Freitas ${ }^{2}$

Samuel Soares Da Silva ${ }^{3}$

\footnotetext{
${ }^{1}$ Unifaminas / Diretor de inovação

${ }^{2}$ Professor Departamento de Administração / Universidade Federal de Viçosa

${ }^{3}$ Mestrando em Administração; Departamento de Administração; Universidade Federal de Viçosa
} 


\section{EDUCAÇÃO EMPREENDEDORA NO ENSINO DE ADMINISTRAÇÃO: A SIMULAÇÃO REALÍSTICA COMO INSTRUMENTO DIDÁTICO}

Resumo: O trabalho analisou a aplicação da metodologia de Simulação Realística (SR) como fonte de promoção da educação empreendedora no ensino da administração. A justificativa se baseia na constatação que a metodologia de ensino predominante nos cursos de Administração é tradicionalmente conteudista e pouco estimula a criatividade e manifestações empreendedoras de forma prática. A pesquisa caracteriza-se como um estudo de campo unicêntrico, realizado no campus da Universidade Federal de Viçosa. O universo estudado foi composto por dois grupos, sendo cinco estudantes de graduação e sete do programa de mestrado ambos em Administração da UFV. O estudo é de abordagem qualitativa e método estudo de caso, tendo por base a metodologia SR seguida de entrevistas semiestruturadas. Os principais achados mostram que a SR pode ser um instrumento didático pedagógico capaz de incrementar recursos utilizados em processos de educação empreendedora nos cursos de administração. Portanto, houve êxito nesta experiência crítico-reflexiva de metodologia ativa.

Palavras-chave: Metodologias ativas. Simulação realística. Inovação. Educação empreendedora.

\section{Introdução}

A sociedade em que vivemos sofreu um processo radical de transformação, tornando-se cada vez mais volátil, incerta, complexa e ambígua, conforme constata o sociólogo Zigman Bauman a partir do conceito de liquidez da modernidade. O cenário atual encontra-se em uma modernidade líquida, na qual a cultura do imediatismo, da individualização e do prazer prevalecem. A transição da sociedade de produção para a sociedade de consumo trouxe diversas mudanças que atingem as esferas sociais, econômicas e políticas (FERREIRA FRANCISCO 2015).

A capacidade para lidar e agir com a complexidade do século XXI é um desafio para os administradores (Le Boterf, 2003, p.69) citado por Andrade (2016), pois estas novas demandas permeiam o campo do conhecimento das competências ao invés de estar estritamente relacionado ao perfil técnico convencional do administrador, o que implica um novo modo de ensino-aprendizagem preocupado com a emancipação e promoção dos envolvidos podendo ser denominado como educação empreendedora.

Neste sentido, do ponto de vista da aprendizagem, a importância dos estudos de Vygotsky é inquestionável, pois ele critica as teorias que separam a aprendizagem do desenvolvimento ao afirmar que entendia que a aprendizagem não era uma mera aquisição de informações, não acontecia a partir de uma simples associação de ideias armazenadas na memória, mas era um processo interno, ativo e interpessoal (NEVES \& DAMIANI, 2006).

$\mathrm{Na}$ abordagem vygotskyana, o homem é visto como alguém que transforma e é transformado nas relações que acontecem em uma determinada cultura. O que ocorre não é uma somatória entre fatores inatos e adquiridos e sim uma interação dialética que se dá, desde o nascimento, entre o ser humano e o meio social e cultural em que se insere. Assim, é possível constatar que do ponto de vista de Vygotsky o desenvolvimento humano é 
compreendido não como a decorrência de fatores isolados que amadurecem, nem tampouco de fatores ambientais que agem sobre o organismo controlando seu comportamento, mas sim como produto de trocas recíprocas, que se estabelecem durante toda a vida, entre indivíduo e meio, cada aspecto influindo sobre o outro (NEVES \& DAMIANI, 2006).

O conceito de educação evoluiu, ultrapassando as fronteiras de espaço e tempo em que o aluno faz o seu período de escolarização, para dar lugar a um processo de aprendizagem ao longo da vida, isto é, possibilitando a cada um a capacidade de saber conduzir a sua vida num mundo onde a rapidez das mudanças se alia ao fenômeno da globalização, e no qual se requer um alto grau de competitividade que, mais do que nunca exigindo a busca por uma educação mais ativa, ou seja, a educação empreendedora (FERREIRA FRANCISCO, 2015).

O relatório The Future of Jobs (WEF, 2016) aponta as tendências das demandas dos empregadores mundiais referente às habilidades esperadas dos futuros candidatos às vagas em suas empresas. Foi identificado dez habilidades mais valorizadas por estes profissionais diante da complexidade do século XXI e ao avanço da economia digital: resolução de problemas, capacidade crítica, criatividade, capacidade de gerenciar e influenciar pessoas, inteligência emocional, tomada de decisão, orientação para o serviço, negociação e flexibilidade. Portanto, a pesquisa sugere que o desenvolvimento de habilidade sociais e emocionais devem ser prioridades para administradores públicos, acadêmicos, organizações e mercado de trabalho.

Sob tal perspectiva entende-se que o conjunto dos sujeitos em situação profissional, independente de cargo, possui capacidades intrínsecas de ação e transformação de seu ambiente organizacional. São sujeitos biopsicossociais que vivenciam prazer, sofrem, adoecem. São, igualmente, carregados de desejos, ambições e sonhos, dotados ainda da necessidade de reconhecimento, cujo sistema psíquico de maneira consciente e muitas vezes inconsciente influencia suas respectivas condutas. Outro pressuposto importante é que a vida coletiva os mobilizam na constituição de identidades profissionais que mais uma vez impactam o meio de trabalho e as organizações (GIUST-DESPRAIRES, 2001).

Assim sendo, à medida que se reconhece a necessidade de se desenvolver o pensamento crítico e as habilidades de raciocínio, e não apenas prover conhecimentos, a criação de ambientes para a mediação das relações indivíduo-trabalho-organização evidenciam-se estratégicos para o desenvolvimento saudável e sustentável da sociedade. Nessa direção, a simulação realística ou simulação de alta fidelidade emerge como possibilidade de alavancar ambientes organizativos mais aderentes à dinâmica contemporânea.

De acordo com Gaba (2007), a simulação realística pode ser entendida como o processo que replica cenários em um ambiente próximo a realidade, com o objetivo de analisar e refletir as ações realizadas de forma segura. A simulação é uma técnica, e não exclusivamente uma tecnologia, que tem por objetivo substituir ou amplificar uma experiência real com supervisão, que evoca substancialmente aspectos do mundo real em um ambiente interativo.

Desse modo, a simulação realística é uma ferramenta que pode ser aplicada em todos os níveis da organização, enfatizando a multidisciplinaridade em diversas situações cotidianas. Especialmente em simulações comportamentais de alta fidelidade e alta complexidade, em que é possível a reflexão sobre as ações realizadas pelos envolvidos com o auxílio de um facilitador que acompanhou o cenário simulado. Esse, por sua vez, deve assumir postura de mediar a discussão em grupo sobre o sentido das ações, os acertos e as oportunidades de melhorias. Também no campo das organizações, a aplicação da metodologia demonstra que 
sujeitos cujas condutas revelam maior capacidade para admitir a incerteza, o conflito e a contradição se mostram mais aptos a lidar com situações mais complexas.

Visando, portanto, como objetivo geral investigar a aplicação da metodologia de simulação realística como forma de fomentar o processo de educação empreendedora na formação de administradores, tendo-se para tal como propósito central analisar implicações da simulação realística na formação de graduandos e mestrandos do curso de administração da Universidade Federal de Viçosa - UFV, face às demandas decorrentes do mercado atual de trabalho em que se inserem. Já como objetivos específicos tem-se: Averiguar o papel da simulação realística em propiciar respostas às transformações que caracterizam o mercado de trabalho em que se inserem os profissionais alvo da pesquisa; Analisar em que extensão a simulação realística se apresenta capaz de desenvolver as competências requeridas, sob a perspectiva dos indivíduos pesquisados; Identificar implicações da simulação realística na construção de vantagens profissionais competitivas; Analisar diferenças e semelhanças quanto à percepção da simulação realística no desenvolvimento das competências requeridas pelos profissionais de administração. Assim sendo, a questão central que orientou a realização deste estudo pode ser assim sintetizada: De que forma a simulação realística enquanto metodologia ativa contribui para inovar e instrumentalizar uma educação empreendedora nos cursos de Administração?

Desse modo, torna-se imperativo investigar as implicações da metodologia de simulação realística como forma de promover uma educação empreendedora na formação de profissionais de Administração de uma Instituição de Ensino Superior, face às demandas decorrentes do mercado atual de trabalho.

\section{Referencial Teórico}

\subsection{Educação de adultos: uma reflexão à luz da andragogia}

Os crescentes avanços tecnológicos e científicos, conforme relatam Silva e Torres (2017), impõem ao profissional do século XXI necessidades específicas que diferem consideravelmente dos objetivos da educação básica, mais centrada em conteúdos introdutórios, e que segue padrões pedagógicos direcionados pelos professores. Ademais, a condição de adulto geralmente leva o educando a ter níveis de interesse e comprometimento que dependem de práticas pedagógicas mais ajustadas à sua maturidade, necessidades profissionais e exigências pessoais. Isso ocorre principalmente nos cursos de graduação, pósgraduação e educação ou formação continuada.

A reflexão sobre o ensino nas universidades é uma tarefa urgente, posto que o Ensino Superior voltado às licenciaturas ou bacharelados, se apresenta como um processo sempre inacabado, no qual tempos, disciplinas, conteúdos e didáticas estão fundamentados, geralmente, em uma perspectiva tradicionalista, conteudista e enciclopedista (CARVALHO, 2016).

Decorre então, uma nova perspectiva: a andragogia, a maneira de aprender dos adultos, estabelecendo-se novas formas metodológicas de ensino e aprendizagem. A teoria andragógica traz novas perspectivas sobre a aprendizagem, lança desafios ao professor universitário e se apresenta como uma ciência que tem como objetivo facilitar a aprendizagem dos adultos e possibilitar que o professor promova a "[...] educabilidade, ou seja, favorecer 
para que os sujeitos, eles próprios, tornem-se construtores e transformadores de sua individualidade, da subjetividade e da própria sociedade (ROMANOWSKI, 2007, P. 115).

Inspirado nos princípios do modelo andragógico, Krajnc (1989) salienta que, após o desenvolvimento infantil, o ser humano, durante a vida adulta atravessa ainda um processo de desenvolvimento físico e psicológico relacionado com o seu status e com as suas responsabilidades sociais perante terceiros, bem como com o seu maior reservatório de experiências, o que torna mais particulares as suas necessidades de aprendizagem. Assim, é preciso considerar que a aprendizagem nos adultos é diferente em extensão e na forma, comparativamente à aprendizagem nas crianças.

De modo geral, é possível registrar que a andragogia e a pedagogia apresentam diferenças bastante significativas em sua forma de abordar o aprendiz, nas metodologias empregadas pelo professor para que ocorra a aprendizagem, bem como na maneira de motivar o aluno. As diferenças básicas entre os dois modelos estão explicitadas na Tabela 1

Tabela 1 - Características do modelo pedagógico e andragógico.

\section{PEDAGÓGICO}

\section{ANDRAGÓGICO}

Relação professor/aluno

Professor é o centro

Mais centrada no aluno
Importa a experiência do professor

Finalidade na obtenção de progressão escolar

Lógica centrada nos conteúdos

Atender a sociedade

Classificações e apreciações

$$
\text { externas }
$$

Experiência do aluno como recurso

Utilidade para enfrentar problemas reais

Resolução de problemas e tarefas

Aplicação na prática da vida diária

Fatores de origem interna

Motivação

Fonte: adaptado de Serguei (1988)

Pelos pressupostos, torna-se necessário entender que aprendizagem do adulto nos remete ao desafio da mudança da postura profissional de "professor" para "facilitador". Como enfatizam Knowles, Holton, Swanson (2009, p. 13) "não podemos ensinar um adulto, mas sim, ajudá-lo a aprender", bem como "estimulá-lo a debater os conceitos e descobrir novas possibilidades adequadas à realidade de cada um, além de considerar outros ambientes de aprendizagem". Contudo, é diferença entre ser um "facilitador" de aprendizagem, e não um "professor" Knowles (2009, p. 275-276).

Todavia, Barros (2018), enfatiza que o facilitador precisa entender a andragogia como um conjunto de princípios de aprendizagem aplicáveis a diversas situações, objetivos, contextos e a pessoas de qualquer idade. $\mathrm{O}$ trabalho com o modelo andragógico pode ser considerado uma "arte" vinculada a muitas ciências como biologia, psicologia clínica, sociologia, psicologia social, administração entre outras. 


\title{
2.2 Metodologias ativas como forma de promover a educação empreendedora
}

Muitos dos desafios de educadores de diferentes áreas do conhecimento estão pautados em encontrar diferentes metodologias que realmente possam contribuir para a melhoria da eficácia da aprendizagem adulta. Inúmeras formas de aprendizagem têm se apresentado no contexto atual de sociedade, mas é preciso compreender as individualidades e diversidades que compõem a nossa sociedade.

A educação, de modo geral, vem sofrendo mudanças gradativas com o passar dos anos, principalmente relacionadas ao avanço da tecnologia, que por sua vez instiga o sistema de ensino vigente a se adaptar aos recursos provenientes dessa transformação tecnológica.

Já Mitre et al. (2008, p. 2136) apontam que "[...] propor um processo de ensinoaprendizagem que pressuponha a bagagem cultural do discente" precisa levar em consideração as competências de cada aluno, de forma a propiciar a melhor forma de aprendizagem. $\mathrm{O}$ aperfeiçoamento de metodologias de aprendizagem no ensino superior, conforme relato de Godoi e Ferreira (2016), tem mobilizado grande número de pesquisadores em diferentes áreas do conhecimento na busca pela excelência da docência. Assim, a Andragogia, conforme relatado anteriormente, ganha corpo na literatura de educação estando presente em algumas metodologias ativas de aprendizagem como forma de promover uma educação empreendedora atuando como uma alternativa às metodologias tradicionais.

Nesse contexto, ainda segundo esses mesmos autores, as metodologias ativas de aprendizagem têm se destacado com uma das formas de promover no discente uma postura empreendedora e ativa em sala de aula, promovendo uma educação empreendedora que é aquela que prioriza a emancipação do aluno inspirando-o a habilidades e atitudes que o fazem praticar o ato de transformar uma realidade, ou seja se empreender (SHEPHERD, 2011).

Contrapondo-se aos métodos tradicionais de aulas expositivas, os métodos ativos de aprendizagem apresentam-se convidativos aos educadores para transformar alunos passivos em alunos ativos durante o processo ensino-aprendizagem. Como afirmam Dalfovo et al. (2017, p. 137):

\begin{abstract}
[...] "a contribuição do educando no processo de ensino é tão relevante quanto o papel do educador, independente de como este conhecimento está sendo abordado, pois como já foi dito, o papel do professor é mediar o ensino e não somente transmiti-lo. Quando o professor consegue captar o estilo de aprendizagem, característico do aluno, a assimilação do conteúdo parece acontecer de forma mais natural, mas na verdade, isto ocorre pelo simples fato de que o conteúdo está sendo apresentado de uma forma mais atrativa ao aluno".
\end{abstract}

Conforme destaca Pinto et al. (2012), o aluno contemporâneo diante das competências éticas, políticas e técnicas exigidas, deve ser capaz de autogerenciar o seu processo de formação. É neste contexto que metodologias ativas de aprendizagem podem conduzir à busca por esta educação de forma empreendedora do discente e ao autogerenciamento e corresponsabilidade pelo seu próprio processo de formação.

As metodologias ativas, enquanto processo de aprendizagem, incluem o discente de forma ativa no ambiente relacionado à sua profissão, ainda na sua formação, estimulando o estudante a buscar respostas de diversos problemas, possibilitando que se coloque em prática, já na graduação, sua capacidade de exame, reflexão, além de proporcionar meios que o leve à produção de novas pesquisas (Mitre et. al., 2008). Assim, por meio de situações reais, ou não, 
os discentes são capazes de resolver os desafios advindos do ambiente social em diferentes contextos por meio dos problemas apresentados (BERBEL, 2011).

De acordo com Barbosa e Moura (2014), a principal diferença entre um ambiente tradicional de ensino para um de aprendizagem ativa é justamente a atitude ativa de pensar em contraste com a atitude passiva, que é associada a métodos tradicionais de ensino. Os autores, porém, destacam que a capacitação dos docentes com novos métodos de aprendizagem não deve acontecer através de decretos regulatórios e, frequentemente, não trazem os resultados esperados se o objetivo é pautado apenas o currículo de formação.

Frente à demanda por competências profissionais específicas do administrador é responsabilidade dos gestores da educação superior assumir este compromisso de transição paradigmática do ensino meramente teórico/expositivo para o ensino ativo, moldando a dinâmica educacional em Instituições de Ensino Superior (BARBOSA ET AL., 2016).

Algumas dessas abordagens comumente descritas por esses autores como a simulação realística são direcionadas a promover uma aprendizagem empreendedora e ativa que podem ser aplicadas para a formação critico-reflexivas do administrador buscando sempre inovar e empreender.

\subsubsection{Simulação Realística como instrumento de educação empreendedora}

$\mathrm{Na}$ busca por novas metodologias ativas de ensino, a Simulação Realística - SR ou simulação de alta fidelidade representa uma promissora possibilidade para formar administradores mais críticos, reflexivos e preparados para a atuação real. A percepção do potencial de tal técnica de ensino vigora em diversas áreas, em especial no treinamento de pilotos no setor da aviação, e mais recentemente, os profissionais da saúde. (Cunha, 2011).

No entanto, somente a partir de 1999, que a simulação realística ganhou maior destaque. O relatório do Institute of Medicine, "To Error is Human", em 1999, apresentou dados alarmantes sobre a segurança do paciente mostrando que cerca de 98.000 pacientes morrem por erros durante a hospitalização nos Estados Unidos, anualmente. O relatório aponta falhas de comunicação e trabalho em equipe como causas de muitos erros e traz recomendações sobre programas de treinamento para equipe interdisciplinar com a incorporação da simulação como método.

É importante destacar que a simulação realística evoluiu e atualmente engloba, não somente as habilidades técnicas, mas o gerenciamento de crises, liderança, trabalho em equipe, raciocínio em situações críticas. Conforme observam autores como Santos et al. (2017), Barreto (2014), Teixeira (2011), a adoção da SR como nova tecnologia educacional consiste em um importante mecanismo facilitador do processo ensino-aprendizagem, pois oferece novas possibilidades para a ampliação da teoria e da prática para o corpo discente.

Segundo Gaba (2009), a simulação pode ser entendida como o processo educacional que replica cenários em um ambiente próximo a realidade, com o objetivo de analisar e refletir as ações realizadas de forma segura. Outra definição proposta pelo autor descreve a simulação como uma técnica, e não exclusivamente uma tecnologia, que tem por objetivo substituir ou amplificar uma experiência real com supervisão, mas que evoca substancialmente aspectos do mundo real em um ambiente interativo.

Pazin e Scarpelini (2007) definem a simulação como uma metodologia que reproduz situações reais permitindo ao aluno um papel ativo na aquisição dos conceitos necessários 
para a compreensão e resolução do problema, enquanto que o professor adota uma postura de condutor ou facilitador. Assim, a simulação realística é retratada como uma ferramenta poderosa de aprendizado que pode ser aplicada em todos os níveis da educação, enfatizando a multidisciplinaridade em diversas situações cotidianas conforme desmonstra a Figura 01 (YPINAZAR, 2006).

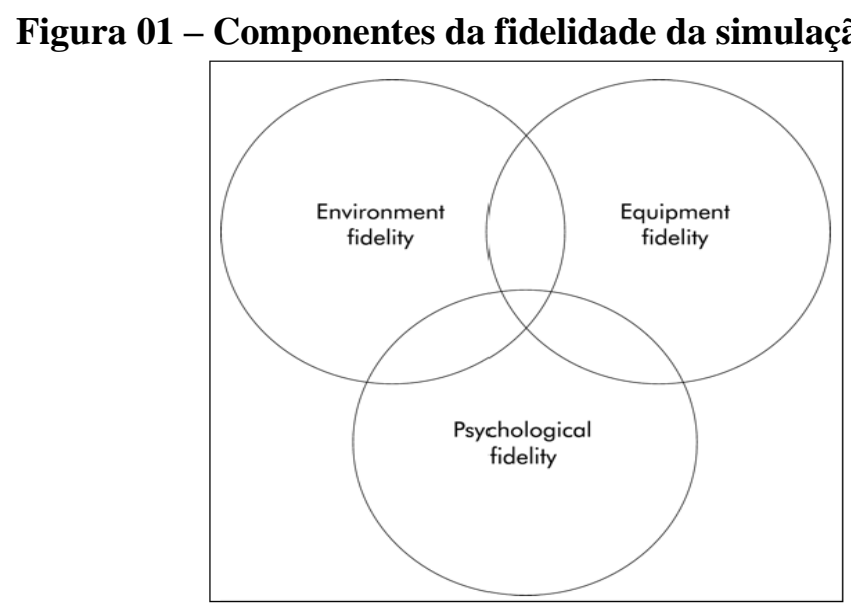

Fonte: Adaptado de Rehmann et al., 1995.

A simulação é uma abordagem que proporciona uma aprendizagem ativa, experiencial. À medida que o aprendizado é consolidado, o foco no conhecimento diminui, passando para competências essenciais e de apoio, a fim de lograr desafios cada vez mais complexos, apresentados ao aprendiz mais experiente (CLAYTON ET AL., 2017).

A efetividade da simulação, segundo Sanches (2016) é revelada como tecnologia de ensino que facilita a aprendizagem quando utilizada sob condições adequadas. Na perspectiva dos professores a simulação contribui com o trabalho em sala de aula, com o processo de aprendizagem do estudante e com a prática docente. Contudo, sua aceitação somente irá ocorrer quando houver apropriação técnica e conceitual por partes dos professores, pois eles têm o compromisso em promover tais práticas para motivar os alunos a se emanciparem e por meio deste método alcançar uma educação que seja empreendedora.

\subsection{O ensino de administração no Brasil e o curso de Administração da UFV}

$\mathrm{O}$ aumento do número de alunos matriculados nos cursos superiores de Administração vem crescendo a cada dia, configurando-o como o curso com maior número de matriculados do Brasil. De acordo com os dados do Censo da Educação Superior/2015, divulgados em outubro de 2016 pelo Instituto Nacional de Estudos e Pesquisas Educacionais Anísio Teixeira - INEP e pelo Conselho Federal de Administração - CFA, o curso de bacharelado em administração é um dos mais ofertados do país, possuindo um total de 793.564 matrículas, quantitativo que representa $12 \%$ do universo de estudantes regularmente matriculados no ensino superior. Além dos cursos de bacharelado em administração, destaca-se um quantitativo de 512.007 matrículas em cursos superiores de tecnologia em administração no Brasil, o que representa $8 \%$ do total de alunos matriculados em instituição de ensino superior (INEP, 2017; CFA, 2017). Em 1995, o número de alunos matriculados era de 195.287 e, em 
2015 (última disponibilização dos dados do Censo do Ensino Superior), 1.330 .483 alunos estavam matriculados (BOLZAN, 2017).

Sabe-se que fatores de competitividade almejados pelos indivíduos ainda em formação ou já nos programas de pós-graduação em administração, centrados na empregabilidade, flexibilidade, inovação, capacidade adaptativa, resiliência, dentre outros, colocam como recorrente o questionamento, sobre a capacidade de os atuais processos de formação efetivamente fomentarem o desenvolvimento e mobilização de tais atributos de competência, em particular, face aos modelos mais tradicionais de ensino vigentes em ampla gama de cursos de graduação - e mesmo pós-graduação - em Administração (HARVEY, 1993).

Nessa direção pode-se constatar que a metodologia de ensino predominante nos cursos de Administração, de modo geral, é tradicionalmente conteudista, pouco estimula a criatividade, a narrativa coerente, o raciocínio livre, o manejo de crises, o trabalho em equipe, o exercício e as relações de liderança. Isto é, em muito pouco contribui no preparo do aluno para atuar na subjetividade e aflorar de forma prática o empreendedorismo.

O curso de administração da UFV, criado em 1976, teve seu reconhecimento em 21/01/1980 pela Portaria do MEC No 91. Nele, a atuação esperada do profissional de administração é que o mesmo seja capacitado a gerir recursos de toda a ordem, mediante o exercício do planejamento, da organização, da direção e do controle, no âmbito das organizações de qualquer natureza ou porte, com vistas à otimização do processo de tomada de decisão, facilitando a resolução de problemas e a vivência organizacional como fatores preponderantes na maximização de resultados. Sabe-se que o administrador pode assumir papéis diferenciados - assessores, executivo, pesquisador, consultor, empreendedor e, ou, professor - em áreas como finanças, mercadologia, operações, logística, estratégia, gestão de pessoas e administração geral (UFV/PRE, 2013).

No sentido de atender a esta gama diversificada de atuação do administrador, a matriz curricular do curso de Administração/UFV encontra-se estruturada num modelo em que o estudante inicialmente tem contato com as disciplinas básicas e posteriormente cursa disciplinas profissionalizantes, numa sequência pré-definida para as disciplinas obrigatórias. Há flexibilidade para selecionar as disciplinas optativas, no decorrer do curso, finalizando com a realização de estágio supervisionado (UFV/PRE, 2013). Tal modelo embora contribua em algum grau para a interdisciplinaridade, interprofissionalidade, motivação e o desenvolvimento de competências, estas não são realizadas na sua plenitude.

Nesse contexto, vislumbra-se a necessidade de buscar práticas educacionais que favoreçam a ampliação do pensamento crítico do estudante de administração, possibilitando sua integração com o ambiente profissional já nos semestres iniciais do curso. Assim, a relevância deste estudo consiste, dessa forma, em propiciar elementos que venham a constatar em que extensão a simulação realística apresenta-se significativa no desenvolvimento de competências profissionais e na educação empreendedora que são requeridas pelas organizações contemporâneas. Dessa forma facilitar e justificar a implementação dessa estratégia em programas de formação de gestores, líderes e empreendedores.

\section{METODOLOGIA}

\subsection{Característica metodológicas e sujeitos de Pesquisa}


A pesquisa que subsidiou a realização deste estudo pode ser caracterizada como um estudo de campo unicêntrico, realizado no campus da Universidade Federal de Viçosa. O estudo pode ser também caracterizado como de abordagem qualitativa, desenvolvido segundo o método de estudo de caso único, tendo por base a adoção da metodologia de Simulação Realística - SR visando proporcionar aos sujeitos de investigação uma experiência próxima da realidade, seguida de entrevistas semiestruturadas. As entrevistas foram realizadas a partir da experiência e narrativa dos indivíduos submetidos a um cenário simulado com alta fidelidade.

O estudo foi realizado com alunos da graduação em administração e profissionais do programa de mestrado também em administração da Universidade Federal de Viçosa. O Departamento de Administração da Universidade Federal de Viçosa foi escolhido para este estudo pelo seu histórico em atuar com excelência no atendimento e na promoção do bemestar e das aspirações sociais, mediante processo integrado de ensino pesquisa e extensão para melhor formação de profissionais. Ademais, existe grande preocupação da instituição em repensar a matriz curricular para melhor alinhar as necessidades do mercado com a formação de seus respectivos alunos. Portanto, configura-se como campo de pesquisa adequado para o presente trabalho.

O cenário simulado foi realizado no prédio da Coordenadoria de Educação Aberta e a Distância - CEAD, da UFV. O CEAD foi utilizado por possuir capacidade já instalada tanto para trazer realismo ao ambiente de simulação escolhido, quanto para captação e transmissão de áudio e imagem para sala de observação e uso no debriefing

O universo estudado foi composto por dois grupos de trabalho, sendo cinco estudantes da graduação em Administração e sete do programa de mestrado em Administração do Departamento de Administração da Universidade Federal de Viçosa. Esta unidade de estudo foi escolhida por conveniência, ou seja, o trabalho foi executado com alunos voluntários. A utilização de uma amostragem não probabilística exige retirar a amostra de uma parcela acessível da população (COSTA, 1977).

Aos integrantes de ambos os grupos foi livremente solicitado a comparecer no dia da simulação pelo professor do departamento da administração. O grupo da graduação ficou composto por um estudante do terceiro período, um do quinto, dois do sétimo e um do oitavo.

O grupo dos integrantes do mestrado, composto por alunos em fase de conclusão da etapa de disciplinas, constituiu-se por quatro alunos com graduação prévia em administração, dois com formação básica em ciências contábeis e outro com formação em agronegócio. Todas as graduações foram concluídas na mesma instituição do programa.

Cabe salientar a solicitação a cada estudante de consentimento livre e esclarecido para participar do estudo, garantindo-se a confidencialidade das informações e seu anonimato. Um exemplo de roteiro para auxiliar a implementação da simulação realística foi apresentado por Fabri (2015), com foco nos profissionais de saúde. Este modelo teórico prático foi construído com o propósito de instrumentalizar a atividade do professor / facilitador na aplicação da simulação realística e resultou em sete unidades de significância: 1. Conhecimento prévio do aprendiz, 2. Objetivos da aprendizagem, 3. Fundamentação teórica, 4. Preparo do cenário, 5. Desenvolvimento do cenário, 6. Debriefing e 7. Avaliação.

\subsection{Coleta de dados}




\subsubsection{Instrumento de coleta de dados}

Os participantes foram estimulados a narrar livremente sobre as experiências vivenciadas junto à metodologia de simulação realística. As respostas não foram condicionadas a uma padronização (Manzini 2004). No entanto, o entrevistador utilizou-se de um roteiro prévio com tópicos que deveriam ser contemplados na entrevista. As questões tiveram origem a partir do problema de pesquisa e buscaram tratar o tema central de uma maneira ampla. O principal objetivo do roteiro foi fomentar a coleta de informações básicas e organizar a interação entre entrevistador e entrevistado

\subsubsection{Estratégia para coleta de dados}

Para a coleta de dados fez-se uso de instrumentos múltiplos. Além de entrevistas o estudo utilizou-se de observação direta e grupos focais envolvendo os participantes. Cabe registrar que cada participante foi entrevistado separadamente e todas as entrevistas foram gravadas. O modelo de entrevista em profundidade é consolidado como um dos caminhos eficazes para compreender e descrever os fenômenos observados. Favorece a investigação e a captação da percepção dos participantes frente a situação vivenciada (CURVELLO, 2002).

\subsection{Tratamento e análise de dados}

Para análise dos dados coletados por meio de entrevistas empregou-se o método de análise de conteúdo por categoria, conforme critérios delineados por Bardin (2014) Segundo o autor, a técnica prioriza a sistematização, interpretação e descrição do conteúdo das informações coletadas, com objetivo de entender o discurso, aprofundar em suas características e extrair os detalhes mais importantes (BARDIN, 2014).

Buscou-se, desse modo, identificar no processo pontos comuns e pontos de divergência em relação à metodologia da simulação realística como caminho para educação empreendedora no curso de administração de maneira a comparar os grupos estudados.

\section{Discussão dos resultados}

Destaca-se que os alunos da graduação, com exceção de um, estavam todos nos dois últimos anos do curso. Enquanto, todos os alunos do mestrado, haviam iniciado o programa há seis meses. $\mathrm{O}$ ambiente acadêmico frequentado por todos os participantes foi apenas a Universidade Federal de Viçosa, mesmo do grupo do mestrado, todos cursaram suas graduações na instituição.

Do total de graduandos e mestrando participantes deste estudo, nota-se que a maioria nunca havia vivenciado em suas respectivas rotinas de sala de aula alguma metodologia ativa de ensino. Entretanto, por meio da conversa, do compartilhamento, da criação de uma atmosfera de liberdade, foi possível construir uma participação efetiva de todos os envolvidos.

Apesar do cenário simulado ter sido o mesmo, cada grupo desenvolveu, durante o debriefing, uma discussão de forma distinta. Assim, por meio da problematização e resgate da cena, estimulou-se a reflexão sobre os principais acontecimentos da simulação, permitindo a mobilização dos domínios cognitivo e afetivo para lidar com uma situação complexa, facilitando a utilização do conhecimento na vida profissional futura dos alunos (TEIXEIRA \& FELIX, 2011). 
No início de cada entrevista, cada participante teve oportunidade de expressar livremente suas percepções em relação à experiência como um todo. Todos gostaram muito da simulação e apontaram em suas considerações como interessante, inovador, melhora a experiência como aluno além de estimular raciocínio e ter potencial para preencher a lacuna teoria-prática apontada por todos como presente nos programas de administração.

Entre os graduandos, capacidade de envolver pessoas/trabalhar em equipe apareceu em três respostas dos participantes, seguida por liderança em duas ocasiões. Na sequência apontaram oportunidade de mais prática, tomada de decisão, entendimento econômico, empreendedorismo, resiliência, empatia, capacidade crítica como importante na formação dos administradores. Entre os mestrandos, lidar com pessoas ganhou destaque em três respostas, seguida de liderança, visão mais holística, conhecimento básico e comunicação em duas.

Em relação ao que efetivamente a metodologia permitiu desenvolver, o grupo da graduação se mostrou mais impactado ao perceber suas respectivas necessidades de ter postura mais firme frente aos problemas a serem enfrentados e ficou explícito na resposta de dois alunos quanto a possibilidade de a simulação melhorar o modo de se comunicar ou expressar. Apesar das falas não serem exatamente iguais entre os grupos as percepções do que consideram importante na formação do administrador e o que a metodologia permitiu desenvolver estão bem alinhadas a suas próprias expectativas. Assim, Sobre a contribuição em potencial da metodologia, ficou evidenciado uma visão muito positiva sobre a experiência como caminho possível para a materialização de viver situações mais práticas, ponto este, recorrente em todas as entrevistas identificando assim como esta metodologia ativa pode influenciar na educação empreendedora dos alunos de administração.

A simulação realística vivenciada pelos participantes dos dois casos mostrou-se como experiência inovadora para a grande maioria. Em ambos os casos os participantes, tanto da graduação quanto do mestrado, consideraram que a adoção da metodologia da simulação pela instituição (UFV) seria muito favorável para o processo ensino-aprendizagem. Estes resultados são similares ao estudo de Leonello et al. (2017), que recomendam a inclusão da simulação como estratégia de ensino, devido a seu potencial para estimular a aprendizagem colaborativa e o desenvolvimento do pensamento crítico, voltados para o autoconhecimento e a melhoria do desempenho no âmbito profissional.

Quanto às fragilidades do cenário executado, a maioria dos participantes (7), considerados os graduandos e mestrandos, não destacaram qualquer ponto negativo.

Finalmente, sobre o debriefing, todos foram unânimes em apontá-lo como a fase mais válida, enriquecedora e inclusiva. Um integrante do mestrado sugeriu a participação de mais facilitadores em uma próxima oportunidade. A plena integração do grupo é objetivo primordial desta etapa na qual o discente pode discutir livremente os acontecimentos vivenciados ou observados instantes antes. Inclusive, o debriefing é realizado imediatamente após a simulação para explorar e ajudar a sedimentar o aprendizado. Isto presta-se tanto a catalisar o aprendizado quanto permite refletir sobre os pontos a serem melhorados (ARTHUR, LEVETT-JONES, KABLE, 2013).

Os achados do nosso estudo corroboram a pesquisa realizada por Costa (2014), onde se destaca que a simulação é uma metodologia dinâmica e promove integração do grande grupo, principalmente, no momento do debriefing. É nesta etapa que todos os discentes podem discutir sobre a cena vivenciada. Corroboram também com este pensamento e com os 
resultados do nosso estudo, os autores Arthur, Levett-Jones, Kable (2013, p. 1358) que afirmam que [...] "o debriefing é fornecido imediatamente após a simulação e o objetivo é explorar e ajudar a consolidar a aprendizagem dos alunos, isso facilita tanto a aprendizagem quanto possibilita a reflexão dos discentes sobre identificar áreas de que estes podem melhorar".

Foi oportunizado aos participantes explicitarem de maneira mais direta suas percepções sobre a possível contribuição da metodologia adotada no sentido de alcançar desenvolvimento de raciocínio, solução de problemas, tomada de decisão, abordagem holística, comunicação efetiva, liderança e emoções. Entre todos os participantes, as respostas foram positivas, variando um pouco a ênfase dada em cada item, mas concordantes.

No mais, a simulação realista coloca os alunos frente situações problemas típicas da prática profissional, demandam mobilização de saberes anteriormente adquiridos e estimula o raciocínio crítico (Valadares \& Magro, 2014). A satisfação dos discentes quanto à metodologia foi grande e, nota-se poucas divergências entre os dois grupos estudados apesar da heterogeneidade dos entrevistados.

Nesse sentido, corroborando os resultados deste estudo, Costa et al. (2013) reflete sobre as metodologias ativas e a simulação realística no processo de ensino aprendizagem numa perspectiva de construção de saberes em que alunos e professores participam efetivamente e, implica em substituir os processos de memorização de informações e de transferência fragmentada do saber de forma vertical.

A visão dos participantes sobre a formação futura administrador de forma empreendedora trouxe percepções diferentes, mas não divergentes, entre os mestrandos e graduandos. Os estudantes de graduação, de modo unânime, apontam a utilização da simulação como um caminho para aproximação da prática e promoção de uma educação empreendedora com a teoria e pautam a discussão sobre a necessidade da utilização de metodologias ativas como a simulação realística no sentido de contribuir para o desenvolvimento de lideranças, atitudes empreendedoras, e também para o aspecto humano e profissional, focando também na necessidade de maior vivência prática.

Já os estudantes de mestrado consideram que além da necessidade de mais prática, é preciso que o ensino em administração possa ter uma visão mais holística do ser humano para que se discuta também o "ser" comportamental. Também mencionam que a administração vem perdendo espaço para outras áreas e precisa evoluir no sentido de incorporar áreas que atualmente não fazem parte do currículo do administrador, mas que poderiam contribuir para uma formação mais dinâmica, menos teórica e mais próxima das demandas do mercado de trabalho, ou seja, uma educação empreendedora.

\section{CONSIDERAÇÕES FINAIS}

Cabe às instituições de ensino a árdua tarefa de responder às demandas da sociedade no que se refere ao mercado de trabalho. As universidades almejam fornecer indivíduos providos de formação suficiente, capazes de atingir a real necessidade vigente. Isso envolve construir um perfil profissional com peculiaridades de internacionalização, manejo de novas tecnologias, visão holística e aprendizado para a vida (GALLEGO, 2012).

Além disso, percebe-se que as recomendações pedagógicas se alinham para conferir novas diretrizes ao sistema de educação que conduzam os estudantes ao desenvolvimento de 
competências ligadas ao profissionalismo. Assim, revisar os processos de ensino e aprendizagem é vital no intuito de se elaborar um novo formato de modelo didático condizente com a vida real e focado na formação de profissionais e cidadãos competentes.

Nesse sentido, ganha destaque o uso de metodologias ativas como instrumento pedagógico de uma educação empreendedora como possível caminho para o desenvolvimento profissional dos estudantes. São metodologias inovadoras com ênfase no processo de ensino, aprendizagem e avaliação ao colocarem o aluno como protagonista, agentes proativos, motivados a buscar com liberdade e autonomia a solução para problemas reais e complexos. Assim, é necessário rever o papel das instituições de ensino a partir de ações coletivas e diretrizes políticas.

No presente estudo, a ênfase recai sobre os cursos de administração, área reconhecidamente estratégica para o desenvolvimento sustentável de qualquer nação. E em relação, especificamente à simulação realística, onde a percepção do grupo participante foi amplamente positiva em vários sentidos. Assim, destaca-se que um dos grandes potenciais da simulação realística é em envolver seus participantes na resolução de problemas e na reflexão mais aprofundada sobre situações reais promovendo assim uma educação empreendedora a estes alunos.

Os participantes também reconhecem potencial para possíveis aplicações da metodologia de forma a atender outras disciplinas da administração. Entretanto, apontam que o principal impedimento recai sobre própria instituição. No mais, apresenta-se recorrente a crítica ao atual modelo de ensino no que tange ao distanciamento da prática. Inclusive, alinhada a visão de futuro dos participantes, a simulação realística é percebida como possibilidade para preencher essa lacuna.

Por outro lado, como já anteriormente mencionado, registram-se poucas divergências em relação às respostas entre os dois grupos estudados apesar da heterogeneidade dos entrevistados. Uma provável explicação reside no fato de todos os participantes terem estudado na mesma instituição e praticamente terem pouco tempo de mercado de trabalho. Mesmo os mestrandos, optaram por ingressar no programa logo após o final da graduação.

Um outro ponto relevante constatado que merece ser mencionado constitui a ausência prévia por parte dos participantes de experiências com metodologia mais ativas de ensino. Por fim, ao que se refere a trabalhos prévios na área de administração sobre simulação realística, nota-se uma ausência completa de trabalho nos bancos de dados pesquisados.

Contudo, o parecer dos envolvidos foi recomendar a metodologia ativa de SR como modelo pedagógico viável em programas de formação de administradores como forma de promover uma educação mais ativa e empreendedora. Pelos achados do trabalho pode-se inferir a possibilidade de êxito na elaboração e implementação de um desenho de ensino crítico-reflexivo, calcado em metodologias ativas, especificamente a SR, numa tentativa de ruptura com a aprendizagem mecânica, conteudista e como forma de promover uma educação empreendedora que influencie a emancipação e a busca por habilidades e atitudes de forma prática dos alunos do curso de administração como caminho para a melhor abstração desta ciência.

Neste sentido novos estudos precisam ser desenvolvidos e divulgados para fornecer evidencias mais concretas, bem como modelos pedagógicos que na busque pela promoção de 
uma educação empreendedora nos cursos de administração. Deste modo, sugere-se a realização de:

- Estudos comparativos da simulação realística com outras metodologias ativas para verificar a retenção de conhecimento e desenvolvimento de competências na promoção da educação empreendedora;

- Estudos que possibilitem o desenvolvimento de instrumentos que facilitem a avaliação e monitorização do impacto das mudanças introduzidas pela simulação realística.

\section{REFERENCIAS}

Berbel NAN. As metodologias ativas e a promoção da autonomia de estudantes. Semina: Ciências Sociais e Humanas. 2011;32(1):25-40.

Bolzan LM. Processos de ensino, de aprendizagem e de avaliação nos cursos superiores de administração sob a percepção de professores e de estudantes. [tese]. Porto Alegre: Escola de Administração, Universidade Federal do Rio Grande do Sul; 2017.

Brandão CFS, Collares CF, Marin HF. A simulação realística como ferramenta educacional para estudantes de medicina. Sci Med. 2014;24(2):187-192.

Carvalho, JR. Andragogia: saberes docentes na educação de adultos. Revista Diálogos Acadêmicos (Fortaleza). 2016.

Conselho Federal de Administração (Brasil). Administração é o curso com maior número de matrículas em 2015. 2018 [acesso em 2018 set 13]. Disponível em: https://www.cfa.org.br/servicos/news/cra/cfa-administracao-e-o-segundo-curso-com-maiornumero-de-matriculas-em-2015.

Conselho Federal de Administração (Brasil). Censo do curso de administração. 2018 [acesso em 2018 set 18]. Disponível em: https://www.cfa.org.br/servicos/formacaoprofissional/censo-dos-cursos-de-bacharelado-em--admnistracao-e-dos-cursos-superiores-detecnologia-nas-diversas-areas-da-administracao.

Clayton MF, Supiano K, Wilson R; Lassche M; Latendresse G. Using simulation in nursing $\mathrm{PhD}$ education: facilitating application of responsible conduct of research principles. J Prof Nurs. 2017;33(1):68-73.

Costa RRO, Medeiros SM de, Martins JCA, Menezes RMP de, Araújo MS de, et al. O uso da simulação no contexto da educação e formação em saúde e enfermagem: uma reflexão acadêmica. Revista Espaço para a Saúde (Londrina). 2015; 6 (1):59-65.

Cunha EVR. O currículo e o seu planejamento: concepções e práticas. Espaço Currículo. 2011;3(2):578-90.

Curvello JJA. Comunicação interna e cultura organizacional. São Paulo: Scortecci; 2002.

Dalfovo MS, Machado MM, Dalfovo O, Aldrovandi MA. Análise da relação dos estilos de aprendizagem na percepção do método de ensino. Rev Adm e Negócios da Amazônia. 2017;9(3):116-138. Doi:10.18361/2176-8366/rara. 
DeAquino CTE. Como aprender: andragogia e as habilidades de aprendizagem. São Paulo: Pearson Prentice Hall; 2008:10-11.

Ferreira Francisco CS. Inserção socioprofissional dos alunos do Ensino Profissional: A importância das soft skills e da formação em contexto de trabalho. [Relatório científicoprofissional de Mestrado em Psicologia da Educação, Desenvolvimento e Aconselhamento] Universidade de Coimbra - Faculdade de Psicologia e de Ciências da Educação. Coimbra, Portugal, 2015.

Gaba DM. The future vision of simulation in healthcare. Simul Healthc. 2007;2(2):126-35.

Gallego LV. Hacia una universidad competente. Rev Ibero Americana de Educação. 2012;58 (2).

Giust-Despraires F. O acesso à subjetividade, uma necessidade social. In: Araújo JNG de. Carreteiro TC (Orgs.). Cenários sociais e abordagem clínica. São Paulo: Escuta; 2001:230243.

Godoi AF de, Ferreira JV. Metodologia ativa de aprendizagem para o ensino em administração: relatos da experiência com a aplicação do peer instruction em uma instituição de ensino superior. Rev Eletrônica de Administração (Online). 2016;15(2).

Harvey D. A condição pós-moderna. São Paulo: Loyola; 1993.

INEP. Sinopses estatísticas da educação superior - graduação. Brasília. [Internet]. 2017 [acesso em 2017 jul 10]. Disponivel em: https://portal.inep.gov.br/web/guest/sinopsesestatisticas-da-educacao-superior.

International Nursing Association for Clinical Simulation and Learning - US (2016).

Standards Committee. INACSL Standards Committee (2016, December). INACSL Standards of best practice: Simulation-enhanced interprofessional education (Sim-IPE). Clin Simul Nurs. 2016;12(Suppl):S34-S38. Doi: https://doi.org/10.1016/j.ecns.2016.09.011.

Knowles MS. The modern practice of adult education: andragogy versus pedagogy. New York: Association Press [Internet]. 1970 [acesso em 2017 set 01]. Disponível em: https://www.cumc.columbia.edu/dept/medicine/hospitalists/downloads/cc4_articles/Education \%20Theory/Andragogy.pdf.

Leonello VM, Leite MMJ, Almeida DM de, Dias CA. Simulação como estratégia para o ensino. Rev Grad (USP). 2017;2(2).

Manzini EJ. Entrevista semi-estruturada: análise de objetivos e roteiros. In: Anais do II Seminário Internacional sobre Pesquisa e Estudos Qualitativos - A pesquisa qualitativa em debate. 2004 mar 26-27. Bauru: USC, SE\&PQ; 2004.

Martorell JL, Arroyo JL. Fundamentos de psicologia. Madrid: Universitária; 2002.

Melo BC, Sant'Anna G. A prática da metodologia ativa: compreensão dos discentes enquanto autores do processo ensino-aprendizagem. Comum Ciênc Saúd. 2012;4(23):327-339. 
Mitre SM, Siqueira-Batista R, Girardi-de-Mendonça JM, Morais-Pinto NM, Meirelles CAB, Pinto-Porto C, et al. Metodologias Ativas de Ensino-Aprendizagem na formação do profissional de saúde: debates atuais. Ciência e Saúde Coletiva. 2008;13(2):2133-2144.

Neves RA, Damiani MF. Vygotsky e as teorias da aprendizagem. UNIrevista. 2006;1(2).

Pazin FA, Scarpelini S. Simulação: definição. Rev Medicina. 2007;40(2):162-166.

Pinto ASS, Bueno MRP, Silva MAFA, Sellmann MZ, Koehler SMF, et al. Inovação didática projeto de reflexão e aplicação de metodologias ativas de aprendizagem no ensino superior: uma experiência com “peer instruction”. Rev Pesq Cient. 2012;9(15): 75-87.

Romanowski JP. Formação e profissionalização docente. 3 ed. Curitiba: Ibpex; 2007.

Silva MLCA, Torres ML. O estado da arte em andragogia: uma análise nas produções científicas. Acta Científica (Engenheiro Coelho). 2017:43-54. DOI: https://dx.doi.org/10.19141/2236-2622/actacientifica.v26.n2.p43-54.

SHEPHERD, D. A. \& PATZELT, H. The New Field of Sustainable Entrepreneurship: Studying Entrepreneurial Action Linking "What Is to Be Sustained" With "What Is to Be Developed". Entrepreneurship Theory and Practice, 2011.

Soares AMJ, Alves RL, Targino EM de MA. Da teoria à prática: a formação do administrador contemporâneo dinamizada por metodologias ativas. Rev Bras de Ens Sup [Passo Fundo]. 2017;3(4):36-58. Doii: https://doi.org/10.18256/2447-3944.2017.v3i4.2195.

Teixeira, INDO, Felix JVC. Simulação como estratégia de ensino em enfermagem: revisão de literatura. Interface-Comunic, Saúde, Educ. 2011;15(39):1173-83.

Universidade Federal de Viçosa (UFV), Pró-Reitoria de Ensino (PRE). Catálogo de graduação 2013. Viçosa: UFV-PRE; 2013.

Valadares AFM, Magro MCS. Opinião dos estudantes de enfermagem sobre a simulação realística e o estágio curricular em cenário hospitalar. Acta Paul Enferm. 2014;27(2):138-143. WEF. New vision for Education: Unlocking the Potential of Technology. [Internet] 2016 [acesso em 2018 dez 15]. Disponível em: https://www3.weforum.org/docs/WEFUSA_NewVisionforEducation_Report2015.pdf.

Ypinazar VA, Margolis SS. Clinical simulators: applications and implications for rural medical education. Rural Remote Health. 2006;6(2):527. 